\title{
A pesca de iscas-vivas no Arquipélago de Fernando de Noronha (PE-Brasil)
}

The fishing of live-baits in the Fernando de Noronha's Archipelago (PE, Brazil)

\author{
G. C. Zeineddine ${ }^{1 *} ;$ W. Barrella ${ }^{2} ;$ M. Rotundo 3 ; M. Ramires ${ }^{4}$

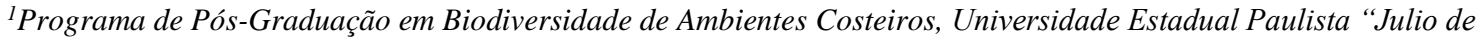 \\ Mesquita Filho”, Pça Infante Dom Henrique, Parque Bitaru, 11330-900, São Vicente-SP, Brasil \\ ${ }^{2}$ Instituto de Ciências da Saúde, Universidade Paulista, Av. Independência, 210, 18087-101, Sorocaba- SP, Brasil \\ ${ }^{3}$ Acervo Zoológico da Universidade Santa Cecília (AZUSC-UNISANTA), Rua Dr. Oswaldo Cruz, 277, 11045-907, \\ Santos-SP, Brasil \\ ${ }^{4}$ Laboratório de Ecologia Humana, Programa de Pós-Graduação em Sustentabilidade de Ecossistemas Costeiros e \\ Marinhos (PPG-ECOMAR) e Auditoria Ambiental (PPG-AUD), Universidade Santa Cecília (UNISANTA), Rua Dr. \\ Oswaldo Cruz, 277, 11045-907, Santos-SP, Brasil \\ *gabizeineddine@hotmail.com \\ (Recebido em 16 de setembro de 2021; aceito em 28 de janeiro de 2022)
}

\begin{abstract}
A pesca artesanal em Fernando de Noronha está diretamente relacionada com a pesca de iscas, pelo fato de os pescadores serem dependentes da mesma para realizar suas capturas de peixes maiores. Este trabalho objetivou caracterizar a pesca de iscas no arquipélago de Fernando de Noronha em relação às espécies de peixes utilizadas como iscas, modo de captura e destino das mesmas. A coleta de dados foi realizada através de questionários semiestruturados com o auxílio da técnica "bola de neve". Os dados foram analisados qualitativamente e quantitativamente, buscando representar o consenso entre os informantes entrevistados. Foram entrevistados 69 pescadores de iscas, os quais utilizam a sardinha (Harengula clupeola) e o garapau (Decapterus macarellus) como principais espécies-alvo, em pescarias embarcadas ou desembarcadas. A sardinha é a isca mais utilizada, capturada com tarrafa, sendo mantidas vivas em compartimentos modificados nas embarcações conhecidos como "viveiros", ou em baldes com água no caso de pescadores desembarcados. O garapau é utilizado quando os pescadores não conseguem capturar a sardinha, sendo pescado com linha de mão durante as noites escuras e conservado vivo também em viveiros. Alguns fatores interferem na captura de iscas, como por exemplo, a restrição de áreas o que, segundo os pescadores, pode prejudicar a atividade pesqueira e, consequentemente, a renda dos pescadores e abastecimento das demandas locais. As informações sobre biologia e ecologia das iscas utilizadas são escassas, o que torna imprescindível o desenvolvimento de estudos que possam guiar medidas de manejo para uma gestão efetiva destes recursos.
\end{abstract}

Palavras-chave: conflito, sardinha, pesca artesanal.

Artisanal fishing in Fernando de Noronha is directly related to bait fishing, as fishermen depends on it to catch larger fish. This work aimed to characterize the bait fishing in Fernando de Noronha Archipelago in relation to the fish species used as baits, their capture methods and destination. Data collection was carried out through semi-structured questionnaires with the aid of the "snowball" technique. Data were qualitatively and quantitatively formed, seeking to represent the consensus among the interviewed informants. Sixty-nine bait fishermen were interviewed, whom use sardines (Harengula clupeola) and garapau (Decapterus macarellus) as their main targets, in embarked or landed fisheries. Sardines are the most exploited bait, caught with casting nets, being kept alive in modified compartments on boats known as "nursery", or in buckets with water in the case of disembarked fishermen. Garapau fishery happens when fishermen are unable to catch sardines, they use hand line during dark nights and also kept alive in nurseries. Some factors interfere on the capture of baits, such as the restriction areas which, according to the fishermen, can harm the fishing activity and, consequently, the fishermen's income and supply of local demands. Information on the biology and ecology of the baits used is scarce, which makes it essential to develop studies that guide management measures for an effective knowledge of these resources.

Keywords: conflicts, sardines, artisanal fishes.

\section{INTRODUÇÃO}

A pesca de pequena escala, ou artesanal, apresenta grande importância econômica por ser responsável por um nível elevado de emprego nas comunidades costeiras, no setor de 
beneficiamento, comércio e captura do pescado. Além disso, promove a manutenção cultural para diversas populações locais, contribuindo para a identidade e fortalecimento social do sistema de crenças e valores agregados na atividade pesqueira [1-3].

No Arquipélago de Fernando de Noronha, a pesca já representou a principal atividade de renda da população local, embora desenvolvida da forma artesanal por consequência das limitações tecnológicas e estruturais que a ilha enfrentou ao longo de décadas [4]. Atualmente, a pesca artesanal é dependente e diretamente relacionada com a captura de iscas, e vem sendo exercida concomitantemente com outras atividades econômicas, porém ainda é praticada tanto como fonte de renda quanto para subsistência, sendo um importante meio da população residente em Fernando de Noronha interagir com o ambiente, abastecer as demandas locais, bem como garantir o sustento das diversas famílias de moradores [5-8].

A utilização de iscas naturais vivas foi iniciada por japoneses há vários séculos, posteriormente exercida por cubanos, açorianos e espanhóis, e introduzida ao Brasil em 1978 por pescadores emigrados de Cabo Verde $[9,10]$. No presente, este método de pesca se encontra regulamentado na legislação brasileira [11] e é utilizado pela maioria dos pescadores artesanais de todo Brasil.

Em Fernando de Noronha a utilização de iscas naturais acompanhou o desenvolvimento da pesca artesanal, porém em 1988 foram criadas duas unidades de conservação com categorias diferentes, uma delas é uma Área de Proteção Ambiental (APA), que permite o uso sustentável do meio ambiente e a outra de proteção integral (Parque Nacional Marinho - PARNAMAR), que modificou o cenário desta atividade em relação ao modo e área de captura, ocasionando o principal e atual agente conflitante entre o órgão gestor e a comunidade pesqueira local [12].

Apesar de existirem estudos sobre a pesca artesanal realizada em Fernando de Noronha [5-8], há uma carência de informações importantes para compreensão da atividade de captura de iscas. Para que os conflitos e a atividade da pesca sejam geridos de forma satisfatória é primordial que haja conhecimento mais detalhado sobre o recurso (iscas) e seu modo de captura. Em vista disso, o objetivo deste trabalho foi realizar o levantamento das espécies de peixes utilizadas como iscas, bem como caracterizar a sua captura em relação ao perfil socioeconômico dos pescadores, modos de captura, comércio e destino das mesmas, a fins de fornecer conhecimento subsidiário para tomadas de decisões no ordenamento da atividade pesqueira local.

\section{MATERIAL E MÉTODOS}

A presente pesquisa foi desenvolvida na ilha de Fernando de Noronha, que é a principal do Arquipélago constituído por 21 ilhas e ilhotas, localizada entre as coordenadas $03^{\circ} 51^{\prime} \mathrm{S}$ e $32^{\circ} 25^{\prime} \mathrm{W}$, a $545 \mathrm{~km}$ de Recife, capital do Estado de Pernambuco e a $360 \mathrm{~km}$ de Natal, capital do Estado do Rio Grande do Norte. A ilha possui aproximadamente $17 \mathrm{~km}^{2}$ de extensão, constituindo $91 \%$ da área total do Arquipélago [13].

Fernando de Noronha conta com diversas enseadas e praias arenosas, sendo elas divididas entre o "mar de fora" e "mar de dentro". No mar de dentro, que fica direcionado para o continente brasileiro, localiza-se o porto Santo Antônio (onde ocorrem os embarques e desembarques) e a maioria das praias arenosas da ilha, sendo um local mais protegido, visto que a posição geográfica local inibe parcialmente a ação dos ventos alísios e das correntes predominantes de sudeste. Já o mar de fora apresenta condições hidrodinâmicas mais intensas, caracterizadas por ondas com forte arrebentação [14].

Sua área encontra-se dividida em duas unidades de conservação, sendo $70 \%$ pertencente ao PARNAMAR (Parque Nacional Marinho), que possui o objetivo de proteção integral do meio ambiente, onde não é permitida a utilização de seus recursos naturais, exceto contemplação e pesquisa. A APA (Área de Proteção Ambiental), que corresponde aos 30\% restantes da área total do Arquipélago, pertence ao grupo de unidades de conservação de uso sustentável, onde é permitido realizar extração dos recursos ambientais, como por exemplo a pesca artesanal comercial e a captura de iscas, porém com atividades devidamente manejadas e ordenadas pelo órgão gestor $[4,15]$. 
A coleta de dados aconteceu no período de janeiro de 2019 a janeiro de 2020, através de entrevistas com o auxílio de questionários semiestruturados contendo questões relacionadas à aspectos socioeconômicos e perfil do pescador, métodos utilizados para captura de iscas, locais de pescaria, tempo médio das pescarias, frequência de captura das iscas, período do dia em que ocorre a atividade, quantidade e tamanho das iscas capturadas, entre outros [7]. Além da coleta de dados, também foram realizadas saídas embarcadas junto aos pescadores para observação e melhor entendimento da atividade [8]. As entrevistas aconteciam no porto Santo Antônio (único porto da ilha) no momento do embarque e desembarque, ou na própria residência dos pescadores, de acordo com a vontade de cada pescador.

Foram considerados como critérios de amostragem para definição dos informantes-chave: o uso de isca viva nas pescarias; idade igual ou superior a 20 anos, tempo de pesca superior a 5 anos e residência em Noronha há pelo menos 5 anos. Para abranger o maior número possível de informantes considerados localmente como especialistas no assunto abordado, foi utilizado o método "bola de neve" [16], onde ao final de cada entrevista, o pescador que está sendo entrevistado indica outro pescador.

Os pontos de captura das iscas foram marcados por GPS (Global Positioning System) e plotados em um mapa através do software ArcGIS. A identificação das espécies utilizadas como iscas ocorreu através de fotos, e consulta de bibliografia especializada [17-28]. A classificação sistemática foi revisada de acordo com Nelson (2006) [29] e a nomenclatura científica segundo Menezes et al. (2003) [30] e Eschmayer (2011) [31].

Os procedimentos adotados nesta pesquisa foram aprovados pelos pescadores através do termo de consentimento livre e esclarecido, assinado no momento das entrevistas, bem como pelo Comitê de ética em pesquisa envolvendo Seres Humanos da Universidade Santa Cecília sob o parecer $n^{\circ} 389.163$, e SISBIO (nº 40953-4).

Os dados foram analisados qualitativa e quantitativamente, buscando representar o consenso entre os informantes entrevistados. O consenso do informante é baseado na concordância entre as respostas dos entrevistados, permitindo analisar, dentre vários aspectos, a importância do uso deste recurso estudado [32]. Assim, as respostas foram agrupadas na forma de porcentagem de citações sobre cada aspecto abordado, ou seja, as respostas mais citadas ou os aspectos mais mencionados foram considerados como informações mais relevantes [33-35].

\section{RESULTADOS E DISCUSSÃO}

Foram entrevistados 69 pescadores artesanais do Arquipélago de Fernando de Noronha, que realizam a pesca de iscas. A idade dos entrevistados variou entre 23 e 72 anos e a maioria é do sexo masculino (98\%). Apenas 23 pescadores são ilhéus, outros são nascidos em localidades como Recife/PE $(28,5 \%)$ e Natal/RN $(8 \%)$ mas residem na ilha desde crianças. A maior escolaridade dos entrevistados foi principalmente o ensino fundamental incompleto (52\%), seguida por ensino médio $(24,1 \%)$ e ensino fundamental completo $(19,4 \%)$. Neste trabalho foram demonstrados apenas os resultados citados por $10 \%$ ou mais dos entrevistados, correspondente a pelo menos 7 pescadores.

A pesca artesanal local destina-se principalmente ao comércio, sendo este mais intenso no porto Santo Antônio, nos restaurantes da ilha, nas residências ou através da estrutura da ANPESCA (Associação Noronhense de Pescadores), utilizada apenas por três pescadores associados para limpar e congelar o pescado. Muitos dos pescadores também trabalham com atividades voltadas ao turismo como condução de turistas (40\%) (guias turísticos), passeios de barco (15\%), funcionários de pousada (15\%) e passeios com pesca esportiva (15\%).

A obtenção de iscas naturais é de extrema importância para a realização da atividade pesqueira em Fernando de Noronha, principalmente porque o petrecho de pesca mais utilizado na pesca artesanal é a linha de mão com isca natural (viva ou morta). O petrecho "linha de mão" consiste em fio de Nylon (variando entre 0,50 e 1,20 milímetros de espessura) enrolada em um bastão de madeira ou um cano de pvc (policloreto de vinila), com anzol simples de tamanho variável (a depender da espécie alvo). A técnica de pesca mais utilizada pelos pescadores é a do "corrico", a qual compreende o arrasto da linha de mão com uma isca viva (ou morta) no anzol 
com o barco em movimento, o que permite que a isca capture com maior facilidade os exemplares de grande porte $[5,7,8,36]$.

A captura de iscas é realizada por todos os pescadores artesanais de Noronha (100\%), tanto os que realizam atividades embarcadas (fins comerciais) quanto os pescadores desembarcados, que capturam os peixes nas praias e costão rochoso (fins comerciais e consumo), no entanto é permitida apenas nas áreas dos limites da Área de Proteção Ambiental (APA) de Fernando de Noronha - Rocas - São Pedro e São Paulo, que corresponde ao mar de dentro.

As principais iscas utilizadas são: a sardinha - Harengula clupeola (Cuvier, 1829) e Harengula jaguana Poey, 1865, (utilizadas por $100 \%$ dos entrevistados), o garapau Decapterus macarellus (Cuvier, 1833) (27\%), iscas artificiais $(15,9 \%)$ e pedaços de peixes $(2,9 \%)$. As características de captura do garapau e sardinha estão demonstradas na Tabela 1. A sardinha representa um importante item na cadeia do pescado para diferentes frotas pesqueiras e regiões distintas, como em diversos países da América Central e no território brasileiro [37-39].

Tabela 1. Caracterização da captura das iscas sardinha e garapau na ilha de Fernando de Noronha $(N=$ número de citações, \%= porcentagem de citações).

\begin{tabular}{|c|c|c|c|c|c|}
\hline \multicolumn{2}{|c|}{ Características da captura } & \multicolumn{2}{|c|}{$\begin{array}{c}\text { Sardinha } \\
\text { (n: 69) }\end{array}$} & \multicolumn{2}{|c|}{$\begin{array}{c}\text { Garapau } \\
\text { (n: 18) }\end{array}$} \\
\hline \multirow{3}{*}{ Modo de captura } & & $\mathbf{N}$ & $\%$ & $\mathbf{N}$ & $\%$ \\
\hline & Tarrafa (malha $12 \mathrm{~mm}$ ) & 69 & 100 & - & - \\
\hline & Linha e anzol & - & - & 17 & 94,4 \\
\hline \multirow{2}{*}{ Local de captura } & Praia & 69 & 100 & - & - \\
\hline & Alto mar & - & - & 16 & 94,4 \\
\hline Época de captura & Ano todo & 61 & 88,4 & 5 & 27,8 \\
\hline \multirow{2}{*}{ Abundância } & Abundante & 62 & 89,9 & 15 & 83,3 \\
\hline & Rara & 8 & 11,6 & 2 & 11,1 \\
\hline \multirow{3}{*}{ Período do dia } & Manhãzinha & 45 & 65,2 & - & - \\
\hline & Manhã e final de tarde & 17 & 24,6 & - & - \\
\hline & Noites escuras & - & - & 16 & 88,9 \\
\hline \multirow{6}{*}{$\begin{array}{c}\text { Frequência da } \\
\text { captura }\end{array}$} & Todos os dias & 33 & 47,8 & - & - \\
\hline & $3 x$ por semana & 13 & 18,8 & - & - \\
\hline & $4 \mathrm{x}$ por semana & 9 & 13,0 & - & - \\
\hline & Sem resposta & - & - & 8 & 44,4 \\
\hline & Pesca quando não tem sardinha & - & - & 3 & 16,7 \\
\hline & $4 \mathrm{x}$ ao mês & - & - & 2 & 11,1 \\
\hline
\end{tabular}

A sardinha é considerada uma isca abundante, sendo predominantemente capturada com tarrafa, que consiste em uma rede circular de malha $12 \mathrm{~mm}$, com uma linha presa em seu centro e chumbos em todo seu perímetro, o que faz com que ela afunde quando é lançada, capturando os peixes que estão em seu raio de ação [40]. A tarrafa é bastante seletiva em relação à espécie alvo a ser capturada, ainda assim os pescadores entrevistados afirmam existir espécies acompanhantes, o que de fato não atrapalha a atividade, se o pescador não tiver interesse no recurso, ele apenas o descarta, ainda com vida.

As espécies de peixes capturadas acidentalmente pela tarrafa são: xira - Haemulon chrysargyreum (Günther, 1858) (18,8\%), chicharro - Caranx crysos (Mitchill, 1815) (15,9\%) e saberê ou sargentinho - Abudefduf saxatilis (Linnaeus, 1758) (15,9\%). No caso de pescadores embarcados o uso destas espécies acompanhantes se dá para o consumo pessoal ou de visitantes que realizam passeios de barco com o pescador, servido no momento do almoço. Os pescadores desembarcados as utilizam como iscas, juntamente com a sardinha capturada, ou vendem para os visitantes (para consumo) juntamente com os peixes comerciais capturados. 
Os pescadores que realizam pescarias de forma embarcada (traineiras - 50\%, caícos 35,5\% ou lanchas 14,5\%) costumam aproximar suas embarcações na região costeira (Figura 1), com profundidade variando entre 3 e 7 metros, de acordo com a localização do cardume a ser capturado, onde visualizam-no e arremessam a tarrafa. Para visualizar o cardume de sardinha, os pescadores observam três fatores: as manchas escuras na água, as "mariscadas", que consiste em perturbações na superfície da água, ou a presença de aves se alimentando no local, conhecido como "comidinha" [8]. Essa atividade é realizada no período da manhã antes de saírem para o mar aberto à procura de peixes maiores e é totalmente influenciada pelas condições do mar e clima.

Já os pescadores desembarcados, localizam a sardinha da mesma forma e realizam a captura de sardinha nas mesmas praias, porém ficam nas pedras (próximo ao costão rochoso) ou entram na água (região beira-mar), no período da manhã, no final da tarde, ou em ambos, onde seguidamente já utilizam a isca viva para realizar a captura de peixes para seu consumo e o excedente para comércio.

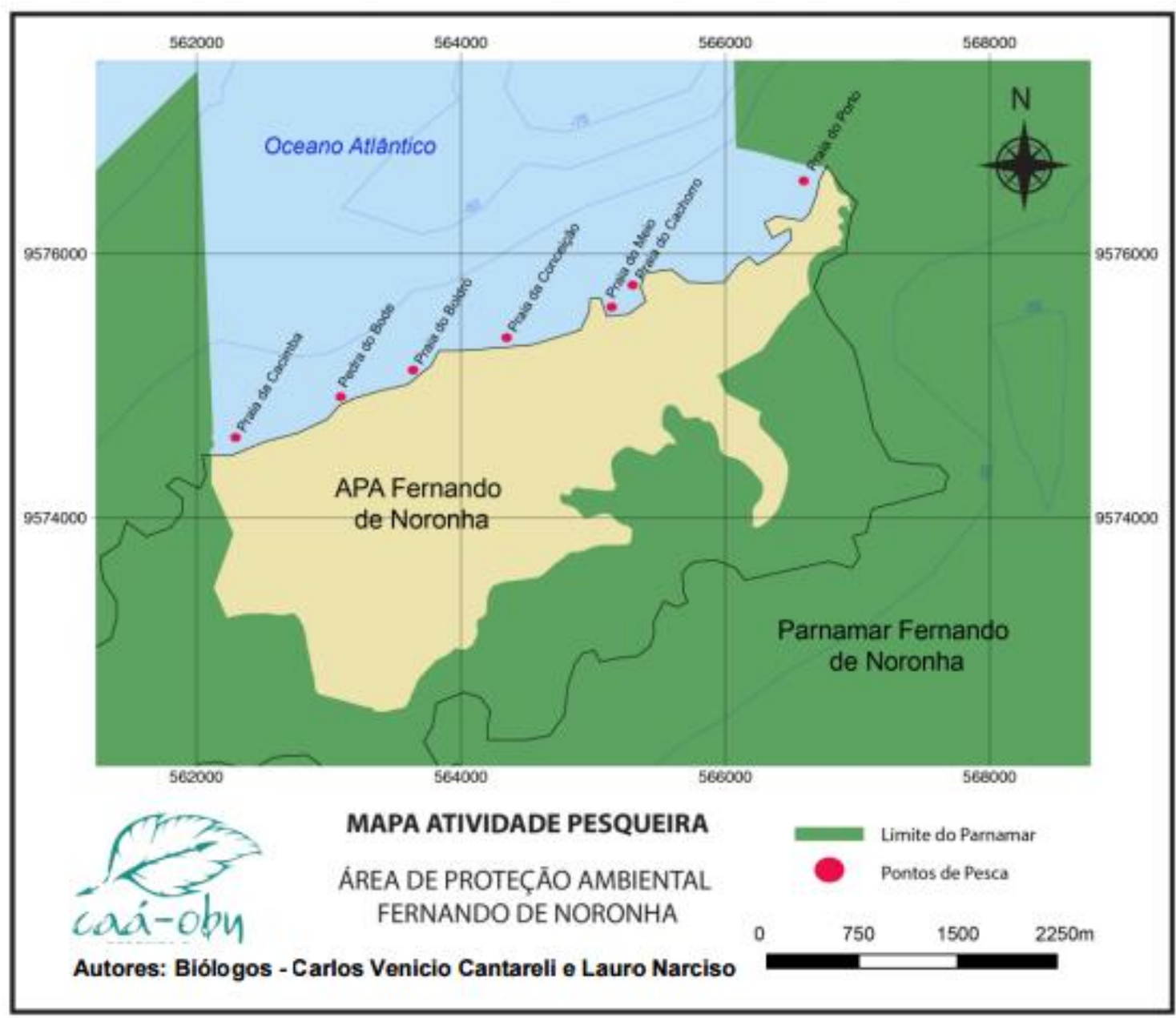

Figura 1: Pontos de captura de sardinha (Harengula clupeola / Harengula jaguana) utilizados pelos pescadores artesanais de Fernando de Noronha/ PE.

O garapau é um recurso mais difícil de ser capturado pelo fato de sua pescaria ser realizada apenas em noites escuras (boca de noite), com linha e anzol (linha de mão e anzol pequeno), o que aumenta o tempo e esforço de captura, fato observado também por Dominguez et al. (2016) [7]. Por este motivo, sua captura ocorre apenas quando os pescadores não são capazes de aproximar suas embarcações das praias para pescar sardinha, devido ao fenômeno conhecido como swell que são ondulações comumente relacionadas com eventos meteorológicos de alta 
intensidade, ou seja, ondulações com um alto potencial energético [41]. Ainda assim, o garapau é considerado uma isca abundante $(83,3 \%)$, e normalmente é pescado nos mesmos pontos (pesqueiros) em que os pescadores realizam a captura dos peixes comerciais (mar aberto/alto mar), ou na praia do porto (Figura 2), com linha de mão e a isca luminosa "sabiki" (composta por um camarão de silicone fluorescente) e auxílio de uma lanterna, utilizando-os seguidamente como isca viva para os peixes de interesse comercial.

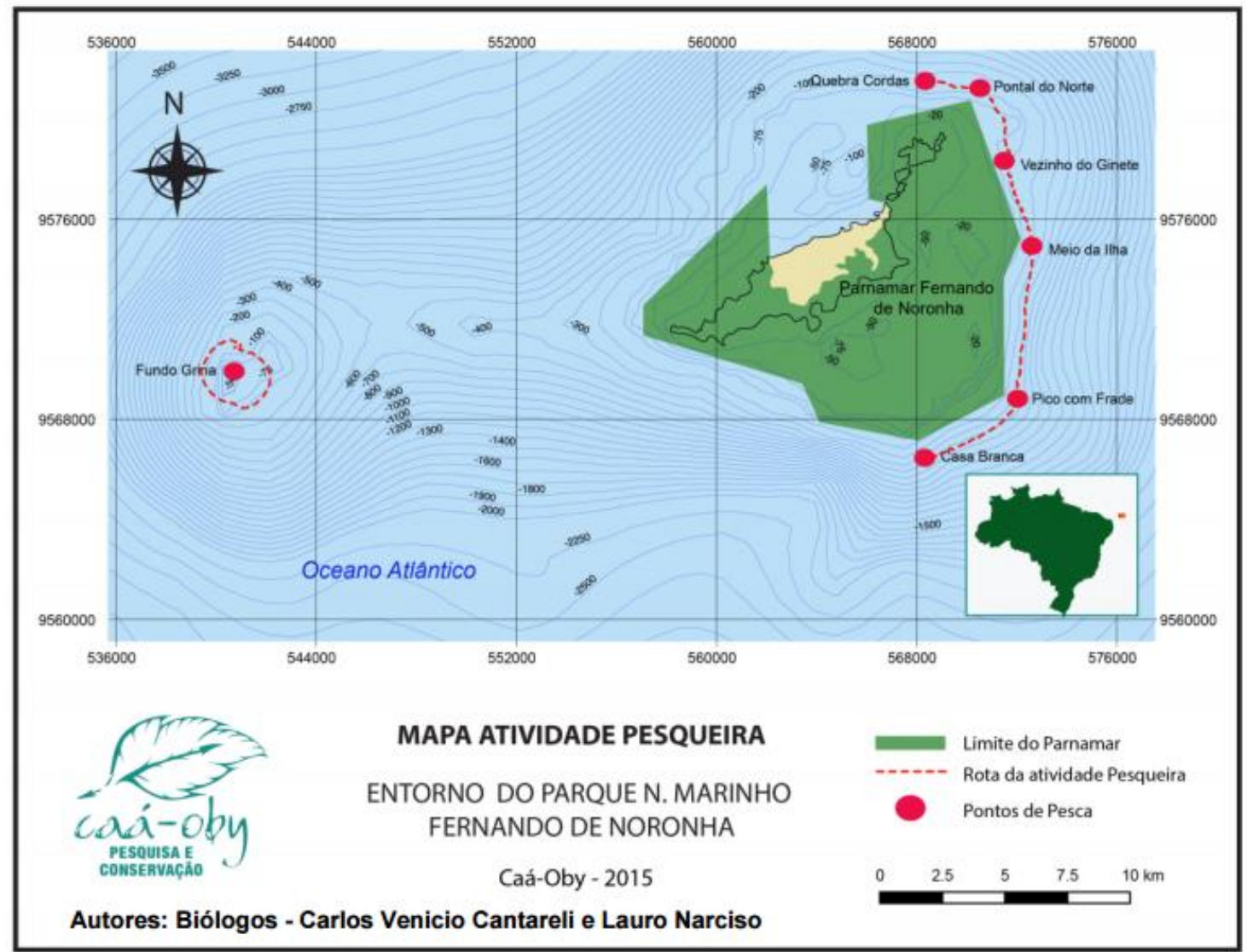

Figura 2: Pontos de captura do garapau (Decapterus macarellus) utilizados pelos pescadores artesanais de Fernando de Noronha/ PE.

A abundância de sardinha e garapau foi estudada por Felix et al. (2006) [42] em um trabalho realizado na Baia de Paranaguá/PR, uma área estuarina com ocorrência destas iscas em praias arenosas, nas quais as maiores abundâncias se deram em estações quentes, pelo fato de haver maior produção primária e, consequentemente, uma maior quantidade de nutrientes, o que favorece a alimentação dos peixes. De forma similar, a produtividade primária em Fernando de Noronha é alta em decorrência do seu clima tropical oceânico, com temperatura consideravelmente estável (amplitude de apenas $4^{\circ} \mathrm{C}$ ), favorecendo a abundância das iscas no local $[14,43]$.

De acordo com os pescadores, são capturados por dia uma média de $4 \mathrm{~kg}$ de sardinha e garapau, podendo chegar a 10,3 $\mathrm{kg}$ e $11,9 \mathrm{~kg}$ de garapau (média dos valores informados por todos os pescadores), com tempo médio de esforço pesqueiro de $2,5 \mathrm{~h}(150 \mathrm{~min})$ respectivamente (Tabela 2). Quando capturam muita sardinha, os pescadores dividem com seus parceiros de outras embarcações para que usem a isca ainda viva, evitando o desperdício. 
Tabela 2 - Valores médios de captura das iscas, segundo pescadores artesanais de Fernando de Noronhal PE.

\begin{tabular}{cccc|ccc|cc}
\hline & \multicolumn{3}{c}{ Biomassa (Kg) } & \multicolumn{2}{c}{ Tempo (min.) } & \multicolumn{3}{c}{$\begin{array}{c}\text { Tamanho do } \\
\text { peixe (cm) }\end{array}$} \\
\hline \hline $\begin{array}{c}\text { Sardinha } \\
(\mathbf{n = 6 9 )}\end{array}$ & 1 & 10,28 & 40 & 50 & 150 & 300 & 8 & 15 \\
$\begin{array}{c}\text { Garapau } \\
(\mathbf{n = 1 8})\end{array}$ & 2 & 11,86 & 30 & 120 & 150 & 300 & 8 & 15 \\
\hline
\end{tabular}

A preferência pela isca viva se dá por $100 \%$ dos pescadores entrevistados, pois afirmam que a eficiência da isca é melhor quando têm movimento, visto que os peixes são predadores e gostam de "atacar", principalmente os peixes grandes como albacora-laje e cavala. Segundo Davis et al. (2006) [44], os estímulos visuais, mecânicos e químicos são muito importantes para o peixe em sua busca por alimento, o que justifica o bom desenvolvimento de uma isca viva para a pesca artesanal.

Para que a isca permanecesse viva no momento da pescaria, os pescadores adaptaram um "viveiro", que consiste num tambor estilo "bombona" de 50 litros que pode ser utilizado amarrado na lateral das embarcações (caícos), ou no interior de embarcações maiores (traineiras) (100\%). As embarcações que utilizam o viveiro em sua popa ou nas laterais de sua casaria, fazem uma abertura em cima do galão para conseguir retirar a isca e nessa mesma abertura é adicionada uma mangueira ligada na bomba d'água (alimentada pelo motor), que mantem o abastecimento, circulação e oxigenação da água do mar [7]. No dos caícos, que utilizam os viveiros imersos no mar, anexados às embarcações, são feitos furos em todo o galão e adicionada uma boia para que o mesmo se mantenha parcialmente submerso à água, assim a movimentação do barco possibilita a oxigenação da água no galão, mantendo a isca viva [8]. Em embarcações do tipo lanchas é utilizado o viveiro (urna) da própria embarcação. Os pescadores desembarcados conservam a isca viva em pequenos baldes com água, onde, após ser utilizadas são jogadas de volta ao mar, ou levadas para a casa, onde são congeladas com sal para que possam ser utilizadas em pescarias seguintes $(14,5 \%$ dos pescadores desembarcados congelam a isca).

Embora sejam produzidos para o mesmo propósito, os viveiros diferem em características e espécies de acordo com as regiões, enquanto em Fernando de Noronha são acoplados ao barco, em outras comunidades, com diferenças de mobilidade na atividade pesqueira, podem permanecer amarrados em locais fixos ou submersos no estuário, onde o pescador busca ou compra as iscas-vivas para o uso imediato [45].

O comércio de iscas é realizado por muitos pescadores no Brasil, como, por exemplo, em uma Reserva de Desenvolvimento Sustentável da Barra do Una, em Peruíbe/SP, onde os pescadores artesanais comercializam camarões para visitantes que realizam pesca esportiva, gerando assim uma fonte de renda alternativa [45]. Outros trabalhos também apontaram a importância socioeconômica do comércio de iscas, como em Corumbá - MS [46], Porto Alegre - RS [47], Pantanal de Mato Grosso do Sul [48] e Santos - SP [49]. Nestes casos, o comércio de iscas-vivas está relacionado com a atividade de pesca esportiva, que em sua maioria são vendidas em maiores quantidades em época de turismo (verão).

Em Fernando de Noronha, alguns pescadores que fretam suas embarcações para a pesca esportiva, também capturam a isca antes das pescarias, fato que contribui para que o comércio da isca viva se torne inviável. Porém, a tarrafa não se enquadra nas artes de pesca esportiva [50], sendo categorizada apenas como artesanal, assim, torna-se necessário melhorias na gestão da pesca esportiva.

Em relação ao comércio de peixes em Fernando de Noronha, Dominguez e colaboradores (2016) [7] destacam os bares, restaurantes e pousadas como os principais compradores/consumidores de peixes na Ilha. De acordo com Lopes et al. (2017) [51] e Mendes et al. (2020) [12], a demanda de peixes é maior que a oferta e o percentual de pescado que é 
vendido em peixarias e cooperativas é de apenas $22 \%$, sendo escasso muitas vezes, fazendo com que comerciantes locais comprem peixes oriundos do continente, principalmente de Natal e Recife. Essa problemática da baixa oferta de peixes para a alta demanda de bares, restaurantes e moradores locais pode estar relacionada ao conflito de pesca de iscas citado pelos pescadores.

Normalmente, áreas marinhas protegidas tendem a limitar pescarias através de manejos que restringem os locais de captura, apetrechos utilizados, espécies capturadas e até quotas de captura [52]. De maneira geral, o fator limitante para a pesca artesanal de Noronha é a disponibilidade de iscas, e a captura de iscas está totalmente influenciada por fatores como estado do mar, chuva, vento e swell. Normalmente o mar de fora, que está inserido PARNAMAR-FN, apresenta ondas com forte arrebentação e um mar agitado, porém entre os meses de novembro e março esse perfil altera, e as ondulações fortes ocorrem no Mar de dentro [53], deixando o mar inadequado para captura de iscas (na zona costeira). Nesses meses os pescadores afirmam observar os cardumes de sardinha dentro de áreas do PARNAMAR, e sentem-se prejudicados pelas limitações de área o que gera conflito com o órgão gestor.

De acordo com os pescadores entrevistados, algumas atitudes já foram sugeridas como uma nova delimitação da área de pesca de iscas, ou ordenamento pesqueiro com dias e horários permitidos para captura de iscas e, até mesmo, uma permissão para a pesca de iscas dentro da área do PARNAMAR apenas para pescadores nativos, exceções estas já acordadas em gestões anteriores (2008 e 2009), mas por descumprimento de normas da parte de alguns pescadores a proibição voltou a ser adotada.

A fim de resolver este "conflito da sardinha", o órgão gestor conduziu algumas oficinas participativas (pesquisadores, pescadores e gestores) entre os anos de 2012 e 2016. Em 2016 um workshop (oficina participativa com os pescadores), gerou como resultado uma proposta de "termo de compromisso" que permitiria a captura de iscas no interior do PARNAMAR-FN. Este termo foi construído em cima de direitos e deveres das partes (pescadores e órgão gestor) e teve uma boa aceitação pelas partes envolvidas, porém não foi consolidado

De acordo com a Instrução Normativa ${ }^{\circ}$ 26/2012, do Instituto Chico Mendes, que trata de termos de compromisso com populações tradicionais em Unidades de Conservação [54], o "termo de compromisso" é um instrumento de gestão e mediação de conflitos, de caráter transitório, a ser firmado entre o órgão gestor e as populações tradicionais em unidades de conservação onde sua presença ou uso de recursos naturais não sejam permitidos (Unidades de Proteção Integral).

Em meados de 2019, o termo de compromisso voltou a ser discutido e, em novembro de 2021 entrou em execução: os pescadores autorizados (53 pescadores tradicionais) estão permitidos a capturar a sardinha (apenas para fins de isca) no interior do PARNAMAR, porém apenas na época de swell e em duas praias, estando totalmente de acordo com as regras explícitas no termo de compromisso.

De acordo com alguns pescadores e moradores antigos da ilha, com a atual liberação da pesca de iscas, o conflito da sardinha está resolvido. Cabe ressaltar que ainda é desconhecido o efeito desta liberação sobre a cadeia trófica local e para que esta resolução seja efetiva, há necessidade de conhecer o recurso explorado (biologia e ecologia), reconhecer o histórico sociocultural em que os pescadores e a atividade de captura de iscas estão inseridos e, só então articular melhores estratégias definitivas de gestão.

Segundo Mendes et al. (2020) [12], se o Termo de 2016 houvesse sido implementado, atualmente a transição já estaria finalizada e a gestão atual estaria sendo feita através de conhecimentos e fatos robustos baseados nas vantagens de acordos coletivos que visam o bemestar sociocultural e ambiental.

Desta forma, com a liberação atual, sugere-se que a atividade de captura de iscas e o monitoramento do termo de compromisso funcionem como um subsídio de dados para que seja possível avaliar o comportamento dos estoques pesqueiros, bem como a identificação, distribuição geográfica, biologia e ecologia das espécies utilizadas como iscas.

Recomenda-se que a coleta destes dados aconteça de forma participativa, através do monitoramento pesqueiro já acordado no termo de compromisso, com oficinas de planejamento de pesquisa envolvendo pescadores, pesquisadores e gestores, acompanhamento diário dos desembarques, preenchimento de fichas (pelos pescadores e monitores), programa voluntário de 
observadores de bordo e observadores de pesca desembarcada. Além de reuniões periódicas para organização, troca de conhecimentos adquiridos, facilitando a gestão participativa.

Nota-se ainda uma lacuna no diálogo entre os pescadores artesanais e os gestores das unidades de conservação que possibilite a facilitação da gestão pesqueira local para o conflito de pesca citado. É extremamente comum este tipo de conflito com populações humanas residentes antes de apropriações de áreas pelo estado, principalmente em unidades de conservação [55-61]. Assim, as informações obtidas nesta pesquisa, tanto sobre o conhecimento dos pescadores quanto à caracterização da pesca, podem ser úteis para administração e ordenamento da pesca de iscas realizadas no Arquipélago.

\section{CONCLUSÃO}

A sardinha e o garapau são as iscas mais utilizadas pelos pescadores, constituindo o elo principal da cadeia produtiva local, porém alguns fatores (condições do mar, clima e limitações da unidade de conservação) interferem sua captura, o que pode prejudicar a atividade pesqueira e, consequentemente a renda dos pescadores e abastecimento das demandas locais.

O conflito local entre pescadores e o órgão gestor decorrente do estabelecimento do Parque Nacional Marinho nas antigas áreas de pesca de iscas fica evidente, porém ferramentas de gestão foram implementadas para tratativa e possível alternativa de resolução.

As informações sobre biologia e ecologia das iscas utilizadas são escassas, o que torna imprescindível o desenvolvimento de estudos que possam guiar medidas de manejo para uma gestão efetiva destes recursos, bem como avaliação da eficácia e impactos do termo de compromisso. Propostas de pesquisas, manejo e monitoramento participativos devem ser incorporados em estratégias de gestão, bem como o conhecimento dos pescadores e as informações oriundas das atividades pesqueiras.

A pesca esportiva também é uma atividade que, aleatoriamente, utiliza espécies de peixes como isca viva, e deve ser ordenada para assegurar que seja praticada de acordo com a legislação específica e quiçá gerar renda aos pescadores artesanais locais através dos serviços relacionados à captura de isca.

\section{AGRADECIMENTOS}

Agradecemos aos pescadores pela disposição e acolhimento durante o ano de estudo, permitindo com que participássemos das atividades de pesca e fornecendo informações sempre que necessário, e ao Instituto Chico Mendes da Biodiversidade pela oportunidade de estadia em Fernando de Noronha através do programa de voluntariado ICMBio - PARNAMARFN.

\section{REFERÊNCIAS BIBLIOGRÁFICAS}

1. Begossi A, Hanazaki N, Peroni M. Knowledge and use of biodiversity Brasilian Hot Spots. Environ Dev Sustain. 2000 Jan;2(1):177-93. doi: 10.1023/A:1011409923520

2. Silvano R. Pesca artesanal e etnoictiologia. In: Begossi A, editor. Ecologia de pescadores da Mata Atlântica e da Amazônia. São Paulo: HUCITEC; 2004. p. 185-20.

3. Ramires M, Rotundo MM, Begossi A. The use of fish in Ilhabela (São Paulo/Brazil): preferences, food taboos and medicinal indications. Biota Neotrop. 2012 Jan;12(1):21-9. doi: 10.1590/S167606032012000100002

4. Brasil. Instituto Chico Mendes de Conservação da Biodiversidade (ICMBio). Plano de manejo da Área De Preservação Ambiental - Fernando De Noronha - Rocas - São Pedro e São Paulo [Internet]. Brasília (DF): MMA; 2017 [citado em 17 jun 2021]. Disponível em: https://www.icmbio.gov.br/portal/images/stories/plano-de-manejo/plano_de_manejo_parna_ferandode-noronha.pdf

5. Lessa RL, Sales MR, Coimbra D, Vaske-Jr T. Análise dos desembarques da pesca de Fernando de Noronha (Brasil). Arq Ciên Mar. 1998 Abr;31(1):47-56. 
6. Dominguez PS, Ramires M, Barrella W, Rotundo M. Preliminary study on fish unloading made by artisanal fishermen of the Archipelago of Fernando de Noronha (Brazil). Unisanta BioScience. 2013 Mar;2(2):120-4.

7. Dominguez PS, Zeineddine GC, Rotundo M, Barrela W, Clauzet M, Ramires M. A pesca artesanal no Arquipélago de Fernando de Noronha (PE). Bol Inst Pesca. 2016 Jun;42(1):241-51. doi: 10.20950/1678-2305.2016v42n1p241

8. Zeineddine CG, Quesada WV, Ramires M, Martins R, Mourato B. A pesca de caíco e o conhecimento ecológico local dos pescadores artesanais do arquipélago de Fernando de Noronha, PE, Brasil. Gaia Scientia. 2021 Abr;15(1):173-92. doi: 10.22478/ufpb.1981-1268.2021v15n1.58349

9. Santos RC, Rodrigues-Ribeiro M. Demanda de iscas vivas para a frota atuneira catarinense na safra de 1998/99: CPUE, composição e distribuição das capturas. Notas Téc Facimar. 2000 Jun;4(1):97-101. doi: 10.14210/BJAST.V4N1.P97-101

10. Lima LGD, Batista VDS. Ethnoictiology studies on Pirarucu (Arapaima mock-ups) in Central Amazon. Acta Amazonica. 2012 Jun;42(3):337-44. doi: 10.1590/S0044-59672012000300005

11. Brasil. Ministério da Pesca e Aquicultura. Instrução Normativa Interministerial $n^{\circ} 10$, de 10 de junho de 2011. Dispõe sobre as normas gerais e a organização do sistema de permissionamento de embarcações de pesca para acesso e uso sustentável dos recursos pesqueiros. Diário oficial da União. 13 jun 2011;150(Seção 1):50. Disponível em: https://www.icmbio.gov.br/cepsul/images/stories/legisla cao/Instrucao_normativa/2011/ini_mpa_mma_10_2011_altrda_regul_permissionamento_completa_alt rd_in_14_2014_in_01_2015.pdf

12. Mendes LF, Lopes PFM, Dario F, Lima SMQ, Coelho JR, Bennemann AB, et al. O "conflito da sardinha": a recente liberação da pesca de sardinhas no Parque Nacional Marinho do arquipélago de Fernando de Noronha. Sociedade Brasileira de Ictiologia. 2020;1(1):1-7.

13. Leite IS, Haimovici M. Biodiversidade e habitat dos polvos de águas rasas das ilhas oceânicas do nordeste brasileiro. In: Mohr LV, Castro JWA, Costa PMS, editores. Ilhas oceânicas brasileiras da pesquisa ao manejo II. Brasília (BR): MMA-SBF; 2006. p.199-214.

14. Serafini TZ, França GB, Andriguetto-Filho JM. Ilhas oceânicas brasileiras: biodiversidade conhecida e sua relação com o histórico de uso e ocupação humana. J Integr Coast Zone Manag. 2010 Mai;10(3):281-301.

15. Brasil. Instituto Brasileiro do Meio Ambiente e dos Recursos Renováveis (IBAMA); Fundação PróNatureza (FUNATURA). Plano de manejo do Parque Nacional Marinho de Fernando de Noronha [Internet]. Brasília (DF): IBAMA/FUNATURA; 1990 [citado em 17 jun 2021]. Disponível em: https://www.icmbio.gov.br/portal/images/stories/biodiversidade/_PARNA_MARINHA_DE_FERNA NDO_DE_NORONHA.pdf

16. Biernacki P, Waldorf D. Snowball sampling-problems and techniques of chain referral sampling. Sociol Methods Res. 1981 Nov;10(1):141-63. doi: 10.1177/004912418101000205

17. Figueiredo JL. Manual de peixes marinhos do sudeste do Brasil. Introdução, cações, raias e quimeras. 1. ed. São Paulo (SP): Museu de Zoologia da Universidade de São Paulo; 1977.

18. Figueiredo JL, Menezes NA. Manual de Peixes marinhos do sudeste do Brasil. Teleostei (1). 1. ed. São Paulo (SP): Museu de Zoologia da Universidade de São Paulo; 1978.

19. Figueiredo JL, Menezes NA. Manual de peixes marinhos do sudeste do Brasil. Teleostei (2). 2. ed. São Paulo (SP): Museu de Zoologia da Universidade de São Paulo; 1980.

20. Figueiredo JL, Menezes NA. Manual de peixes marinhos do sudeste do Brasil. Teleostei (5). 5. ed. São Paulo (SP): Museu de Zoologia da Universidade de São Paulo; 2000.

21. Fischer W. FAO species identification sheets for fishery purposes. Western Central Atlantic (fishing área 31). 7. ed. Roma (IT): FAO; 1978.

22. Menezes N, Figueiredo JL. Manual de peixes marinhos do sudeste do Brasil. Teleostei (3). 3. ed. São Paulo (SP): Museu de Zoologia da Universidade de São Paulo; 1980.

23. Menezes N, Figueiredo JL. Manual de peixes marinhos do sudeste do Brasil. Teleostei (4). 4. ed. São Paulo (SP): Museu de Zoologia da Universidade de São Paulo; 1985.

24. Carvalho-Filho A. Peixes da costa brasileira. 3. ed. São Paulo (SP): Melro; 1999.

25. Araújo ME, Teixeira JMC, Liveira AM. Peixes estuarinos marinhos do Nordeste brasileiro: Guia ilustrado. 1. ed. Pernambuco (PE): Editora UFC; 2004.

26. Marceniuk AP. Chave para a identificação das espécies de bagres marinhos (Siluriformes, Ariidae) da Costa Brasileira. Bol Inst Pesca. 2005 Out;31(2):89-101.

27. Sampaio CLS, Nottingham MC. Guia para identificação de peixes ornamentais brasileiros. 1. ed. Brasília (BR): IBAMA - MMA; 2008.

28. Gomes UL, Signori CN, Gadig OBF, Santos HRS. Guia para a identificação de tubarões e raias do Rio de Janeiro. 1. ed. Rio de Janeiro (RJ): Technical Book; 2010.

29. Nelson JS. Fishes of the world. 4. ed. New York (NY): John Wiley and Sons; 2006. 
30. Menezes NA, Buckup PA, Fiqueiredo JL, Moura RL. Catálogo das espécies de peixes marinhos do Brasil. 1. ed. São Paulo (SP): Museu de Zoologia da Universidade de São Paulo; 2003.

31. Eschmayer WN. Catalog of fishes [Internet]. Electronic version 30/11/2011 [acessado em 9 jan 2021]. Disponível em: https://www.calacademy.org/scientists/projects/eschmeyers-catalog-of-fishes

32. Silva VA, Nascimento VT, Soldati GT, Medeiros MFT, Albuquerque UP. Técnicas para análise de dados etnobiologicos. In: Albuquerque UP, Lucena RFP, Cunha LVF, editores. Métodos e técnicas na pesquisa etnobiológica e etnoecológica. Recife (PE): Nupeea; 2010. p. 207-22.

33. Paz VA, Begossi A. Ethnoichthyology of Galviboa fishermen of Sepetiba Bay, Brazil. J Ethnobiol. 1996 Jul;16(2):157-68.

34. Silvano RAM, Begossi A. Local knowledge on a cosmopolitan fish Ethoecology of Pomatomussaltatrix (Pomatomidae) in Brazil and Australia. Fish Res. 2005 Mai;71(1):43-58. doi:10.1016/j.fishres.2004.07.007

35.Zeineddine GC, Oliveira KS, Ramires M, Barrella W, Guimarães JP. Percepções dos pescadores artesanais e a pesca acidental de tartarugas marinhas na reserva de desenvolvimento sustentável Barra do Una, Peruíbe, São Paulo, Brasil. Ethnoscientia. 2018 Jun;1(3):1-13. doi: 10.22276/ethnoscientia.v3i0.60

36. Sazima I, Krajewski JP, Bonaldo R, Sazim C. A vida dos peixes em Fernando de Noronha. 1. ed. Campinas (SP): Terra da Gente; 2013.

37. Bezerra RCF. Relação peso-comprimento da Sardinha-bandeira, Opisthonema oglinum (Le Sueur) no estado do Ceará. Arquivo de Ciências do Mar. 1968 Abr;8(12):225-7.

38. Nóbrega MF, Lessa RP. Descrição e composição das capturas da frota pesqueira artesanal da região Nordeste do Brasil. Arquivo de Ciências do Mar. 2007 Jan;40(2):64-74.

39. Sá GG, Marinho RA, Conceição RNL. Primeira abordagem sobre a pesca da sardinha bandeira, Opisthonema oglinum (Le Sueur, 1818) em Caponga, Cascavel - Ceará, Crasil. Arquivo de Ciências do Mar. 2012 Abr;45(1):13-24.

40. David GS, Castro PMG, Maruyama CL. Artes de pesca artesanal nos reservatórios de Barra Bonita e Bariri: monitoramento pesqueiro na Bacia do Médio Rio Tietê. Bol Inst Pesca. 2016 Març;42(1):2949. doi: 10.20950/1678-2305.2016v42n1p29

41. Collard, F, Ardhuin F, Chapron B. Routine monitoring and analysis of ocean swell fields using a spaceborne SAR. J Geoph Res. 2008 Fev;30(1):1-13.

42. Felix F, Spach C, Hackradt C, Wet A. Abundância sazonal e a composição da assembléia de peixes em duas praias estuarinas da Baía de Paranaguá, Paraná. Revista Brasileira de Zoociências. 2006 Ago;8(1):35-47.

43. Marques FA, Bittar B, Maria S. Caracterização e classificação de neossolos da Ilha de Fernando de Noronha (PE). Revista Brasileira de Ciência do Solo. 2007 Jul;31(6):1553-62. doi: 10.1590/S010006832007000600032

44. Davis MW, Spencer MM, Ottmar ML. Behavioral responses to food odor in juvenile marine fish: Acuity varies with species and fish length. J Exp Mar Biol Ecol. 2006 Jan;32(8):1-9. doi: 10.1016/j.jembe.2005.04.029

45.Zeineddine GC, Barrella W, Rotundo MM, Clauzet M, Ramires M. Etnoecologia da pesca de camarões usados como isca viva em Barra do Uma, Peruíbe (SP/Brasil). Revista Brasileira de Zoociências. 2015 Out;16(1):67-83.

46. Moraes AS, Espinosa LW. Captura e comercialização de iscas vivas em Corumbá, MS. Corumbá. Pantanal. Embrapa Pantanal-Bol. de Pesquisa e Desenvolvimento (INFOTECA-E). 2001 Abr;21(1):137.

47. Banducci JR, A. Turismo cultural e patrimônio: a memória pantaneira no curso do rio Paraguai. Horizontes Antropológicos. 2003 Ago;9(20):117-40. doi: 10.1590/S0104-71832003000200007

48. Catella AC, Mascarenhas RO, Albuquerque PP, Albuquerque FF, Albuquerque ERM. Sistemas de estatísticas pesqueiras no Pantanal, Brasil: aspectos técnicos e políticos. Pan-Am J Aquat Sci. 2008 Abr;3(3):174-92.

49. Barros LC, Alves PMF, Silva NJR, Henriques MB. Cadeia produtiva do camarão branco utilizado como isca viva na pesca amadora da baixada santista, estado de São Paulo. Inf Econ. 2014 Nov;44(6): 23-35.

50. Brasil. Lei $\mathrm{n}^{\circ} 11.959$, de 29 de junho de 2009. Dispõe sobre a Política Nacional de Desenvolvimento Sustentável da Aquicultura e da Pesca, regula as atividades pesqueiras. Diário Oficial da União. 30 jun 2009;122(Seção 1):1-3. Disponível em: http://www.planalto.gov.br/ccivil_03/_ato20072010/2009/lei/111959.htm

51. Lopes PFM, Mendes L, Fonseca V, Villasante S. Tourism as a driver of conflicts and changes in fisheries value chains in marine protected areas. J Environ Manage. 2017 Set;20(1):123-34. doi: 10.1016/j.jenvman.2017.05.080 
52. Mcclanahan TR, Cinner J, Kamukuru AT, Abunge C, Ndagala J. Management preferences, perceveid benefits and conflicts among resource users and managers in the Mafia Islands Marine Park, Tanzania. Environ Conserv. 2009 Dez;35(4):340-50.

53. Leite TS, Haimovici M, Lins JE. A pesca de polvos no Arquipélago de Fernando de Noronha, Brasil. Bol Inst Pesca. 2008 Set;34(2):271-80.

54. Brasil. Instrução Normativa $\mathrm{n}^{\circ} 26$, de 04 de julho de 2012. Estabelece diretrizes e regulamenta os procedimentos para a elaboração, implementação e monitoramento de termos de compromisso entre o Instituto Chico Mendes e populações tradicionais. Diário Oficial da União. 06 julho 2012; (Seção 1):84-85. Disponível em: http://www.in.gov.br/autenticidade.html

55. Arruda R. "Populações tradicionais" e a proteção dos recursos naturais em Unidades de Conservação. Ambient Soc. 1999 Dez;2(3):5-14. doi: 10.1590/S1414-753X1999000200007

56. Medeiros R, Irving M, Garay IA. Proteção da natureza no Brasil: evolução e conflitos de um modelo em construção. Rev Desenvolv Econ. 2004 Jan;6(9):83-93.

57. Giglio VJ, Freitas MO. Caracterização da pesca artesanal com rede de camboa na Reserva Extrativista do Cassurubá, Bahia. Biotemas. 2013 Jan;26(2):249-59. doi:10.5007/2175-7925.2013v26n2p249

58. Almeida MW, Rezende BR. Uma nota sobre comunidades tradicionais e unidades de conservação. Revista do Centro de Estudos Rurais. 2013 Set;7(2):1-12.

59. Joventino FKP, Lianza S, Johnsson RMF. Pesca artesanal na Baía de Ilha Grande, no Rio de Janeiro: conflitos com unidades de conservação e novas possibilidades de gestão. Política Social. 2013 Jan;12(23):159-82. doi: 10.5007/2175-7984.2013v12n23p159

60. Fontes CFL, Guerra AJT. Conflitos socioambientais na APA de Cairuçu (Paraty-RJ) à luz da sobreposição com unidades de conservação de diferentes categorias. Geousp - Espaço e Tempo. 2016 Mai;20(1):178-93. doi: 10.11606/issn.2179-0892.geousp.2016.85275

61. Casal FC, Souto FB. Conhecimentos etnoecológicos de pescadores da Resex Marinha Baía do Iguape sobre ecologia trófica em ambiente de manguezal. Ethnoscientia. 2018 Jan;1(3):1-15. doi: 10.22276/ethnoscientia.v3i0.129 